\title{
Synthesis of 2-Substituted Benzo[b]furans/furo-Pyridines Catalyzed by $\mathrm{NiCl}_{2}$
}

\author{
Rong Zhou *, Yanli Ding and Mili Yang \\ College of Chemical Engineering, Xinjiang Agricultural University, Urumqi 830052, China; \\ dingyanli628@163.com (Y.D.); yml18299157312@163.com (M.Y.) \\ * Correspondence: zrhg@xjau.edu.cn
}

Received: 4 November 2019; Accepted: 27 November 2019; Published: 3 December 2019

\begin{abstract}
The first Ni-catalyzed tandem synthesis of 2-substituted benzo[b]furans/furo-pyridines from 2-halophenols and 1-alkynes was explored under $\mathrm{Cu}$-free and phosphine-free conditions. The protocol was carried out with $\mathrm{NiCl}_{2} / 5$-nitro-1, 10-phenanthroline in DMA ( $N, N$-dimethylacetamide) at $120^{\circ} \mathrm{C}$. It was found to be simple, cost effective, and have a wide substrate scope. Additionally, the method is compatible with heteroaryl substrates, resulting in the formation of 2-substituted benzo[b]furans/furo-pyridines in reasonable to good yields.
\end{abstract}

Keywords: $\mathrm{Ni}$; benzo[b]furan; coupling-cyclization reaction

\section{Introduction}

2-substituted benzo[b]furans/furo-pyridines are important building blocks in biologically active compounds such as anti-inflammation agents and anti-fungal activities (Scheme 1) [1-6]. Due to these excellent properties, the synthesis of these skeletons has become a hot spot in recent years [7,8]. Recently, York, Panli, and co-workers showed the coupling of unsaturated hydrocarbons with heteroaryl and aryl compounds using Pd catalysis [8,9]. Following their work, several methods were developed to synthesize 2-substituted benzo[b]furan/furo-pyridines [10-13]. However, to obtain these skeletons, noble metals (such as $\mathrm{Pd}$ and $\mathrm{Rh}$ ), air sensitive phosphine ligands, or rigorous conditions usually seem to be necessary [14-17].

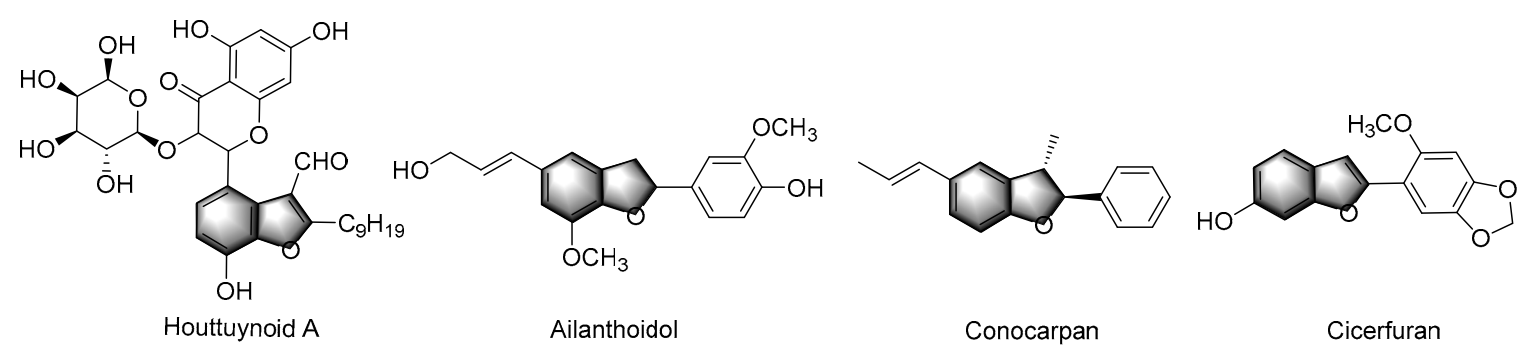

Scheme 1. Some 2-substituted benzo[b]furans/furo-pyridines with biologically active.

$\mathrm{Ni}$ is a superior substitution in catalysis reactions because it is less expensive, air stable, and less toxic [18-20]. However, it has not been used in the construction of 2-substituted benzo[b]furans/furo-pyridines except in one heterogeneous example. Wang Lei et al. developed a catalytic system of ultrafine nickel(0) powder $(100 \mathrm{~nm}) / \mathrm{CuI} / \mathrm{PPh}_{3}$ to synthesize 2-phenylbenzo[b]furan with a 75\% yield in 2004 [21]. Herein, we report on an inexpensive, $\mathrm{Cu}$-free, and phosphine-free method for the construction of 2-substituted benzo[b]furans/furo-pyridines by Ni-catalyzed intermolecular cyclization of 2-iodopehenols or 2-bromophenols and 1-alkynes. 


\section{Results and Discussion}

For optimization studies of 2-substituted benzo[b]furan synthesis, 2-iodophenol 1a and phenylacetylene 2a were chosen as the model substrates (Scheme 2). At first, a series of nickel salts were screened and $\mathrm{NiCl}_{2}$ was found to be the best, affording the most results and the corresponding product $3 \mathbf{a}$ in an $80 \%$ yield (Table 1 , entry 1 ). Various bases were screened to identify the optimized condition where weak and organic bases such as $\mathrm{KHCO}_{3}$ and $\mathrm{Et}_{3} \mathrm{~N}$ (triethylamine) were found to be unsuitable for this transformation (Table 1, entries 10-11, 16-17). However, a strong base like $\mathrm{NaOH}$ could promote this cyclization to give the title product with the yield of $80 \%$ (Table 1 , entry 1 ). Solvents have a great influence in this reaction, so some solvents with different polarities were selected for this reaction. The effect of the solvent was also studied and the data showed that DMA provided the best result, while others like DMF ( $\mathrm{N}, \mathrm{N}$-dimethylformamide), toluene, $\mathrm{H}_{2} \mathrm{O}$, etc. produced lower yields (Table 1, entries 18-23).

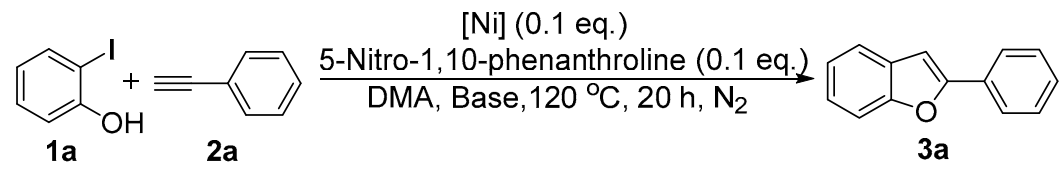

Scheme 2. The model reaction.

Table 1. Optimization of reaction conditions ${ }^{1}$.

\begin{tabular}{|c|c|c|c|c|}
\hline Entry & {$[\mathrm{Ni}]$} & Base & Solvent & Yield/\% \\
\hline 1 & $\mathrm{NiCl}_{2}$ & $\mathrm{NaOH}$ & DMA & 80 \\
\hline 2 & $\mathrm{NiCl}_{2}$ & $\mathrm{NaOH}$ & DMA & $47^{2}$ \\
\hline 3 & - & $\mathrm{NaOH}$ & DMA & 0.8 \\
\hline 4 & $\mathrm{Ni}($ dppe $) \mathrm{Cl}_{2}$ & $\mathrm{NaOH}$ & DMA & 26 \\
\hline 5 & $\mathrm{Ni}(\mathrm{dppp}) \mathrm{Cl}_{2}$ & $\mathrm{NaOH}$ & DMA & 16 \\
\hline 6 & $\mathrm{Ni}\left(\mathrm{PPh}_{3}\right)_{2} \mathrm{Cl}_{2}$ & $\mathrm{NaOH}$ & DMA & 41 \\
\hline 7 & $\mathrm{Ni}\left(\mathrm{PCy}_{3}\right)_{2} \mathrm{Cl}_{2}$ & $\mathrm{NaOH}$ & DMA & 13 \\
\hline 8 & $\mathrm{Ni}(\mathrm{COD})_{2} \mathrm{Cl}_{2}$ & $\mathrm{NaOH}$ & DMA & 28 \\
\hline 9 & $\mathrm{NiSO}_{4}$ & $\mathrm{NaOH}$ & DMA & 75 \\
\hline 10 & $\mathrm{NiCl}_{2}$ & $\mathrm{NaHCO}_{3}$ & DMA & 0.6 \\
\hline 11 & $\mathrm{NiCl}_{2}$ & $\mathrm{KHCO}_{3}$ & DMA & 0.7 \\
\hline 12 & $\mathrm{NiCl}_{2}$ & $\mathrm{Na}_{2} \mathrm{CO}_{3}$ & DMA & 2 \\
\hline 13 & $\mathrm{NiCl}_{2}$ & $\mathrm{Cs}_{2} \mathrm{CO}_{3}$ & DMA & 1 \\
\hline 14 & $\mathrm{NiCl}_{2}$ & $\mathrm{~K}_{3} \mathrm{PO}_{4}$ & DMA & 26 \\
\hline 15 & $\mathrm{NiCl}_{2}$ & $\mathrm{KOH}$ & DMA & 74 \\
\hline 16 & $\mathrm{NiCl}_{2}$ & $\mathrm{Et}_{3} \mathrm{~N}$ & DMA & 0.1 \\
\hline 17 & $\mathrm{NiCl}_{2}$ & pyridine & DMA & 0.1 \\
\hline 18 & $\mathrm{NiCl}_{2}$ & $\mathrm{NaOH}$ & $\mathrm{DMF}$ & 56 \\
\hline 19 & $\mathrm{NiCl}_{2}$ & $\mathrm{NaOH}$ & 1,4-Dioxane & $0.2^{3}$ \\
\hline 20 & $\mathrm{NiCl}_{2}$ & $\mathrm{NaOH}$ & Toluene & $0.6^{3}$ \\
\hline 21 & $\mathrm{NiCl}_{2}$ & $\mathrm{NaOH}$ & $\mathrm{H}_{2} \mathrm{O}$ & -3 \\
\hline 22 & $\mathrm{NiCl}_{2}$ & $\mathrm{NaOH}$ & n-BuOH & $0.1^{3}$ \\
\hline 23 & $\mathrm{NiCl}_{2}$ & $\mathrm{NaOH}$ & $\mathrm{t}-\mathrm{BuOH}$ & -4 \\
\hline
\end{tabular}
${ }_{1}^{1}$ Reaction conditions: 1a $(1 \mathrm{mmol}), \mathbf{2 a}(1.2 \mathrm{mmol})$, Base $(2 \mathrm{mmol})$, [Ni] $(0.1 \mathrm{mmol})$, 5-nitro-1, 10-phenanthroline
$(0.1 \mathrm{mmol}), \mathrm{DMA}(2 \mathrm{~mL}), 120{ }^{\circ} \mathrm{C}, 20 \mathrm{~h}, \mathrm{~N}_{2} ;{ }^{2}$ in air; ${ }^{3} 100{ }^{\circ} \mathrm{C} ;{ }^{4} 80^{\circ} \mathrm{C}$.

Ligands play an important role in the metal catalyzed coupling reaction and so the effect of $\mathrm{N}$-ligands was investigated (Scheme 3). It was shown that the diamine ligand 5-nitro-1,10-phenanthroline L14 was the most effective ligand. The result revealed that a ligand with a rigid skeleton could make the reaction work more smoothly than that with a flexible one. The ligand with large steric hindrance could hinder the process of the coupling-cyclization reaction (L2-L4, L8-L9, L13). Other bidentate N-ligands with a rigid skeleton such as 4-methyl-1,10-phenanthroline 
(L11), and 1,7-dichloro-1,10-phenanthroline (L12) were found to be less efficient for the conversion, with $72 \%$ and $62 \%$ yields, respectively.

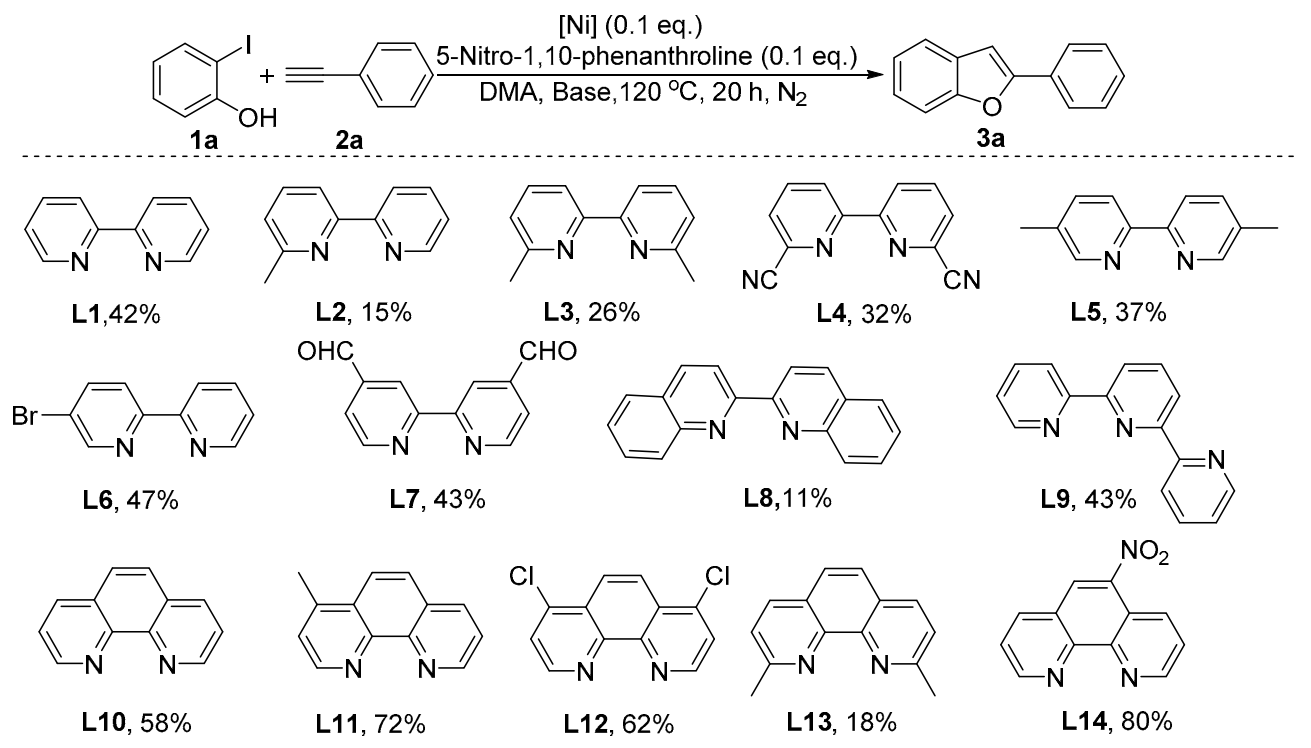

Scheme 3. Screen of ligands. Reaction conditions: 1a (1 mmol), 2 a (1.2 mmol), $\mathrm{NiCl}_{2}(0.1 \mathrm{mmol}), \mathbf{L}$ (0.1 mmol), $\mathrm{NaOH}(2 \mathrm{mmol}), 120^{\circ} \mathrm{C}, 20 \mathrm{~h}, \mathrm{GC}$ yield.

Under the optimized reaction conditions, the functional group tolerance of this reaction was explored (Scheme 4). 2-iodophenols with electron-withdrawing and electron-donating groups could all react with phenylacetylene $2 \mathbf{a}$ and obtain the corresponding products $(\mathbf{3 a}-\mathbf{3 g})$. EWG (electron-withdrawing groups) with more steric hinderance such as 4 - $t$-butyl reduced the reactivity and gave a $37 \%$ yield ( $3 \mathbf{b})$. Heteroaryl substrates contain $N$, which has the potential to combine to nickel, thus poisoning the catalyst. Nevertheless, these heteroaryl materials were all completed smoothly in this system (3c-3d, $\mathbf{3 n} \mathbf{n}-\mathbf{3} \mathbf{x})$. It is noteworthy that 2-iodo-6-methylpyridin-3-ol coupled with 5-bromo-3-iodopyridin-2-ol easily during this system, giving $52 \%$ and $35 \%$ yields of the products (3c, 3d). The alkynes bearing $-\mathrm{OCH}_{3},-\mathrm{CH}_{3},-\mathrm{CH}_{2} \mathrm{CH}_{2} \mathrm{CH}_{3},-\mathrm{COOCH}_{3},-\mathrm{F}$, and $-\mathrm{Br}$ groups all reacted successfully and produced the desired compounds (3h-3n) in reasonable to good yields (30-75\%). 3-ethynylpyridine was also found to be suitable during this one-pot reaction condition $(3 n-3 s)$. When reacted with the large steric hindrance material 4-t-butyl-2-iodophenol, it produced 3-(5-(t-butyl)benzofuran-2-yl)pyridine 3o with an $89 \%$ yield. When 6-methyl-2-iodo-pyridinol was used to cyclize with various 1-alkynes, such as 4-bromo-phenylacetylene, 4-methyl-phenylacetylene, 4-propyl-phenylacetylene, and the corresponding 2-substituted furo-pyridines can be achieved with medium yields $(3 \mathbf{t}-3 \mathbf{w})$. Since 2-bromophenols are less reactive and not susceptible to this transformation, the $\mathrm{Ni}$ catalyzed system has not been reported in the literature with tandem synthesis. Our results show that the procedure works well in the presence of 2-bromophenol, 2-bromo-6-methylpyridin-3-ol, 2-bromo-4-methylphenol, and even 2-bromopyridin-3-ol as starting materials (3a, 3c, $\mathbf{3 x}-\mathbf{3 y})$. 


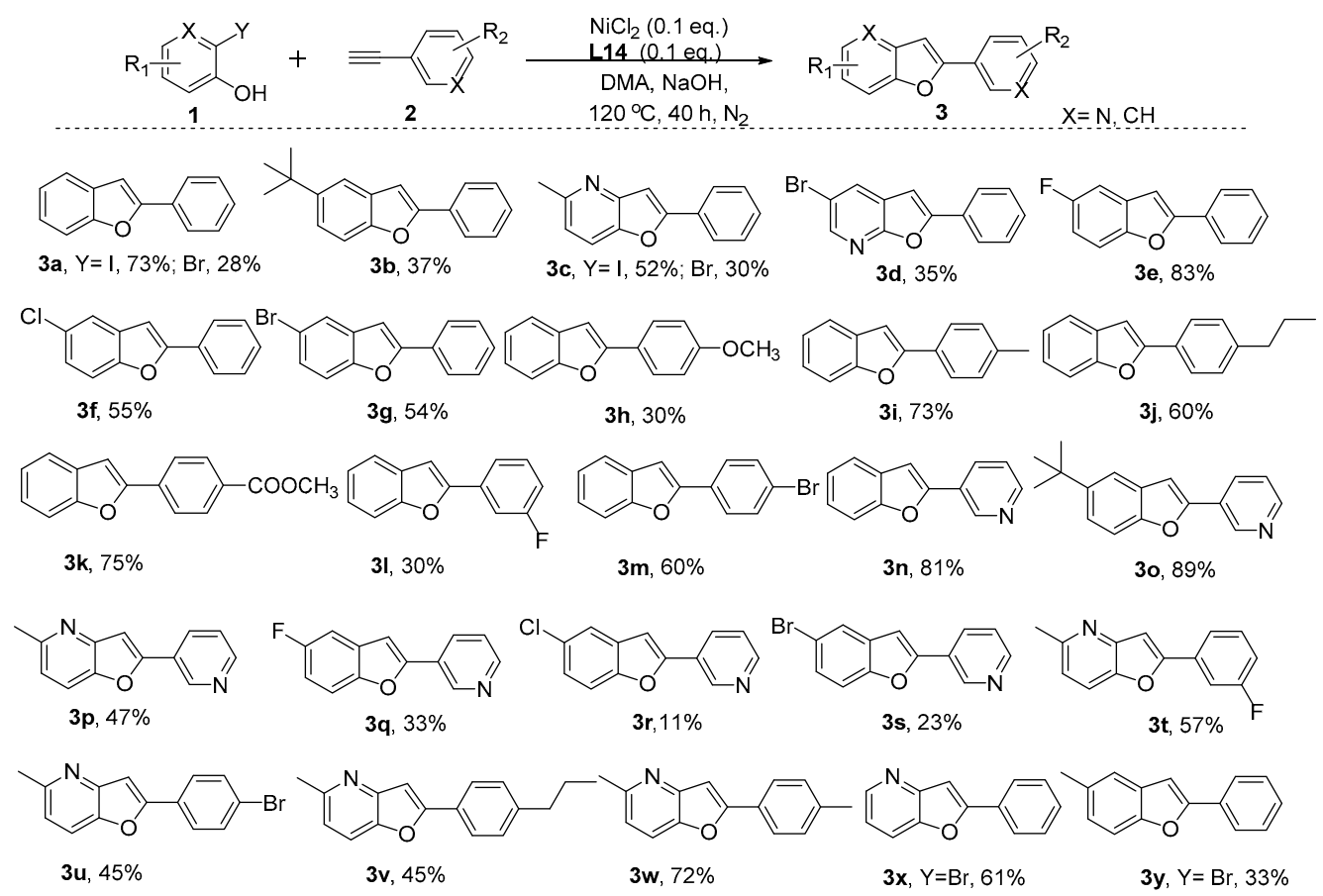

Scheme 4. The exploration of the universality of substrates. Reaction conditions: 1 (1 mmol), 2 $(1.2 \mathrm{mmol}), \mathrm{NiCl}_{2}(0.1 \mathrm{mmol}), \mathbf{L 1 4}(0.1 \mathrm{mmol}), \mathrm{NaOH}(2 \mathrm{mmol}), 120{ }^{\circ} \mathrm{C}, 40 \mathrm{~h}$, isolated yield.

\section{Materials and Methods}

All chemicals were purchased from commercial companies. All were used as received except for some liquid materials that were sensitive to light and moisture (DMA) being purified prior to use. ${ }^{1} \mathrm{H}$ NMR $\left({ }^{1} \mathrm{H}\right.$ Nuclear Magnetic Resonance) and ${ }^{13} \mathrm{C}$ NMR $\left({ }^{13} \mathrm{C}\right.$ Nuclear Magnetic Resonance) spectra were measured on a VARIAN 400-MR. Mass spectroscopy data of the products were collected with a MS-EI (Mass spectrometry-Electron ionization) instrument. All products were isolated by chromatography on silica gel (300-400 mesh) using petroleum ether $\left(60-90^{\circ} \mathrm{C}\right)$. Compounds described in the literature were characterized by ${ }^{1} \mathrm{H}$ NMR and ${ }^{13} \mathrm{C}$ NMR spectroscopy and compared to the reported data, detailed information in Supplementary Materials.

$\mathrm{NiCl}_{2}(0.1 \mathrm{mmol})$, Ligand $(0.1 \mathrm{mmol}), 2$-halophenol (1 mmol), 1-alkynes $(1.2 \mathrm{mmol}), \mathrm{NaOH}$ ( $2 \mathrm{mmol})$, and degassed DMA ( $2 \mathrm{~mL}$ ) were added successively into a dried Schlenk tube with a magnetic bar under nitrogen. The reaction was performed at $120^{\circ} \mathrm{C}$. At the end of reaction, the solution was cooled to room temperature and water $(3 \mathrm{~mL})$ was added. The mixture solution was extracted with ethyl acetate $(3 \times 3 \mathrm{~mL})$. The organic layer was dried over $\mathrm{MgSO}_{4}$, then filtered and purified with silica gel chromatography (petroleum ether) to give a corresponding product.

\section{Conclusions}

In conclusion, a novel, and simple route was developed for the synthesis of 2-substituted benzo[b]furans/furo-pyridines via a tandem Sonogashira coupling-cyclization sequence of 2-iodophenols or 2-bromophenols and 1-alkynes catalyzed by $\mathrm{Ni}$ with $\mathrm{Cu}$-free and phosphine-free in a reasonable to good yield.

Supplementary Materials: The following are available online at http:/www.mdpi.com/2073-4344/9/12/1019/s1, Table S1: Optimization of reaction conditions.

Author Contributions: Conceptualization, R.Z.; methodology, R.Z.; investigation M.Y.; resources, R.Z.; data curation, Y.D.; writing —original draft preparation, R.Z.; writing—review and editing, R.Z.; visualization, R.Z.; supervision, R.Z.

Funding: This research was funded by the Natural Science Foundation of Xinjiang Province (no. 2016D01B18). 
Conflicts of Interest: The authors declare no conflict of interest.

\section{References}

1. Heravi, M.M.; Zadsirjan, V. Recent Advances in the Synthesis of Benzo[b]furans. Adv. Heterocycl. Chem. 2015, 117, 261-376.

2. Kwiecień, H.; Smist, M.; Kowalewska, M. Recent Development on the Synthesis of Benzo[b]- and Naphtho[b]furans: A Review. Curr. Org. Synth. 2012, 9, 529-560. [CrossRef]

3. Jian, J.; Fan, J.; Yang, H.; Lan, P.; Li, M.; Liu, P.; Gao, H.; Sun, P. Total Synthesis of the Flavonoid Natural Product Houttuynoid A. J. Nat. Prod. 2018, 81, 371-377. [CrossRef] [PubMed]

4. Zhihai, K.; Ying-Yeung, Y.; Gavin Chit, T.; Xiao-Shui, P. Progress in Heterocyclic Chemistry; Elsevier Ltd.: Amstertan, The Netherlands, 2015; pp. 203-246.

5. Patricia, M.P.; Angela, R.A.; Maria, C.M.Y.; Astréa, M.G.; Vanderlanda, S.B. Nor-Lignans from the leaves of Styrax ferrugineus (Styracaceae) with antibacterial and antifungal activity. Phytochemistry 2000, 55, 597-601.

6. Chen, P.C.; Tsai, W.J.; Ueng, Y.F.; Tzeng, T.T.; Chen, H.L.; Zhu, P.R.; Huang, C.H.; Shiao, Y.J.; Li, W.T. Neuroprotective and Antineuroinflammatory Effects of Hydroxyl-Functionalized Stilbenes and 2-Arylbenzo[b]furans. J. Med. Chem. 2017, 60, 4062-4073. [CrossRef] [PubMed]

7. York, S.; Makoto, T.; Kazuhiko, S.; Yoshiaki, N.; John, H.F. Anti-Markovnikov Hydroheteroarylation of Unactivated Alkenes with Indoles, Pyrroles, Benzofurans, and Furans Catalyzed by a Nickel-N-Heterocyclic Carbene System. J. Am. Chem. Soc. 2015, 137, 12215-12218.

8. Jiang, P.; Guo, M.; Fu, L.; Wen, Y.; Shen, X.; Zhou, L. $\left[\left(\mathrm{PhCH}_{2} \mathrm{O}\right)_{2} \mathrm{P}\left(\mathrm{CH}_{3}\right)_{2} \mathrm{CHNCH}\left(\mathrm{CH}_{3}\right)_{2}\right]_{2} \mathrm{PdCl}_{2} / \mathrm{CuI}$ as Cocatalyst for Coupling-Cyclization of 2-Iodophenol with Terminal Alkynes in Water. Catalysts 2018, 8, 136. [CrossRef]

9. Arcadi, A.; Cacchi, S.; Marinelli, F. Palladium-Catalyzed Reaction of 2-Hydroxyaryl and Hydroxyheteroaryl Halides with 1-Alkynes: An Improved Route to the Benzo[b]furan Ring System. Synthesis 1986, 9, 749-751. [CrossRef]

10. Thanh, T.; Milad, M.; Ky, K.A.L.; Olafs, D. General Method for Functionalized Polyaryl Synthesis via Aryne Intermediates. J. Am. Chem. Soc. 2014, 136, 8568-8576.

11. Zhou, R.; Wang, W.; Jiang, Z.J.; Wang, K.; Zheng, X.L.; Fu, H.Y.; Chen, H.; Li, R.X. One-pot synthesis of 2-substituted benzo[b]furans via Pd-tetraphosphine catalyzed coupling of 2-halophenols with alkynes. Chem. Commun. 2014, 50, 6023-6026. [CrossRef] [PubMed]

12. Zbigniew, R. NHC-Catalyzed Organocatalytic Asymmetric Approach to 2,2-Disubstituted Benzofuran-3(2H)-ones Containing Fully Substituted Quaternary Stereogenic Center. Catalysts 2019, 9, 192. [CrossRef]

13. Alexandre, B.; Karl, G.P.J.; Ning, Y.; Cheuk-Wai, T.; Ingmar, P.; Xiaodong, Z.; JanE, B. Synthesis of Benzofurans and Indoles from Terminal Alkynes and Iodoaromatics Catalyzed by Recyclable Palladium Nanoparticles Immobilized on Siliceous Mesocellular Foam. Chem. Eur. J. 2017, 23, 12886-12891.

14. Chandan, S.; Prakasham, A.P.; Manoj Kumar, G.; Raymond, B.J.; Prasenjit, G. One-Pot Tandem Hiyama Alkynylation/Cyclizations by Palladium(II) Acyclic Diaminocarbene (ADC) Complexes Yielding Biologically Relevant Benzofuran Scaffolds. ACS Omega 2018, 3, 1740-1756.

15. Abir, S.; Pragati, P.; Wahidur Rahaman, S.M.; Kuldeep, S.; Akshi, T.; Pierre, D.H.; Jitendra, B.K. A Triflamide-Tethered N-Heterocyclic Carbene-Rhodium(I) Catalyst for Hydroalkoxylation Reactions: Ligand-Promoted Nucleophilic Activation of Alcohols. Chem CatChem 2017, 9, 1397-1401.

16. Shohei, O.; Kohei, T.; Hiromichi, F.; Mitsuhiro, A. Cycloisomerization between Aryl Enol Ether and Silylalkynes under Ruthenium Hydride Catalysis: Synthesis of 2,3-Disubstituted Benzofurans. Org. Lett. 2017, 19, 2422-2425.

17. Chen, Z.P.; Zhou, Y.; Shui, M.Z.; Liu, F. CuI Catalyzed Domino Coupling-Cyclization of 2-iodo-phenols and 1-alkynes to the Synthesis of 2-substituted Benzo[b]furans/furo-pyridines. Tetrahedron Lett. 2019, 60, 133-136. [CrossRef]

18. Lin, C.Y.; Power, P.P. Complexes of Ni(I): A "rare" Oxidation State of Growing Importance. Chem. Soc. Rev. 2017, 46, 5347-5399. [CrossRef] [PubMed]

19. Michael, N. Sustainable Catalysis: With Non-endangered Metals, Part 1; The Royal Society of Chemistry: Cambrige, UK, 2016; pp. 407-468. 
20. Zimmerman, P.; Limberg, C. Activation of Small Molecules at Nickel(I) Moieties. J. Am. Chem. Soc. 2017, 139, 4233-4242. [CrossRef] [PubMed]

21. Wang, L.; Li, P.; Zhang, Y. The Sonogashira Coupling Reaction Catalyzed by Ultrafine Nickel $(0)$ Powder. Chem. Commun. 2004, 35, 514-515. [CrossRef] [PubMed] 